\title{
Bioeconomic modeling of optimal harvest time in Nile tilapia (Oreochromis niloticus) considering size heterogeneity and minimum marketable size
}

\author{
Patricia Borrego-Kim ${ }^{1}$, Roger Domínguez-May² \\ Andrea G. Monroy-Borrego ${ }^{3} \&$ Mariel Gullian-Klanian ${ }^{1}$ \\ ${ }^{1}$ Universidad Marista de Mérida, Mérida Yucatán, México \\ ${ }^{2}$ Departamento de Recursos del Mar, Centro de Investigación y Estudios Avanzados \\ Instituto Politécnico Nacional, Mérida, Yucatán, México \\ ${ }^{3}$ Centro de Biotecnología-FEMSA, Tecnológico de Monterrey, Monterrey, Nuevo León, México \\ Corresponding author: Mariel Gullian Klanian (mgullian@marista.edu.mx)
}

\begin{abstract}
Size dispersion in farmed fish has a substantial impact on production's bioeconomic performance, directly affecting net profits. This work's objective was to develop a bioeconomic model based on experimental data to identify the optimal harvest time (OHT) for Nile tilapia Oreochromis niloticus. The bioeconomic model considered four minimum marketable sizes $(M m s=350,400,450$, and $500 \mathrm{~g})$. Organisms were selected by size with different coefficients of variation $(\mathrm{CV})$. Therefore, they were reared under two growth strategies: heterogeneous size ( $\mathrm{HT}=44-155 \mathrm{~g}$; $\mathrm{CV} 25.5 \%)$ and homogeneous size $(\mathrm{HM}=87-112 \mathrm{~g}$; CV 5.9\%). The HT system-generated tradable biomass of $99.30 \%$ in an OHT of 196 days with a net profit of USD 3,551.61 and a Mms of $350 \mathrm{~g}$. However, the HM system achieved greater marketable biomass $(99.53 \%)$ in less time $(\mathrm{OHT}=$ 181 days) with a net profit of USD 3,327.96 for the same Mms. The Mms of $500 \mathrm{~g}$ had the lowest net benefit in both systems. The HM strategy earned an additional $10.66 \%$ of incomes, indicating that the reduction in size dispersion positively impacted profits. The developed model provides a new perspective regarding the management of heterogeneity and size homogeneity in commercial production of Nile tilapia in intensive systems.
\end{abstract}

Keywords: Oreochromis niloticus; tilapia; bioeconomic; size heterogeneity; optimal harvest time; aquaculture

\section{INTRODUCTION}

Aquaculture is an essential agricultural practice for food security worldwide (Klinger \& Naylor, 2012; FAO, 2016; Føre et al., 2018) and Nile tilapia (Oreochromis niloticus) is one of the most popular species (Cai et al., 2018). Size dispersion occurs naturally in the population of tilapia (Barki et al., 2000; Borrego-Kim et al., 2020), and directly affects the profitability (Arnason et al., 1992), since there is a minimum marketable size $(\mathrm{Mms})$ with commercial value. The effect of size dispersion is a recurring phenomenon beyond the inherent stochastic; such as stocking density, feeding conditions, temperature, and ration size (Barbosa et al., 2006; Peacor et al., 2007; Santos et al., 2008; Gullian et al., 2012; GullianKlanian \& Arámburu-Adame, 2013; Domínguez-May et al., 2020). The problem of size heterogeneity in aqua- culture has been addressed with various management practices, including pre-selection or partial harvests (Palada de Vera \& Eknath, 1993; Pérez, 2014) as well as some market strategies (Huang \& Chiu, 1997; Gasca-Leyva et al., 2008; Domínguez-May et al., 2011, 2020).

Population dynamics studies and the determination of the optimal harvest time (OHT) have allowed managing and reducing uncertainty in aquaculture production (Llorente \& Luna, 2016). Stochastic bioeconomic models for structured populations based on the weight of organisms make it possible to simulate production and economic performance through the use of probability functions (Martínez \& Seijo, 2001; Seijo, 2004; Sánchez-Zazueta \& Martínez-Cordero, 2009; Shamshak \& Anderson, 2009; Moreno-Figueroa et al., 2018; Núñez-Amao et al., 2019). For this purpose, discrete and continuous models are used; for example,

Corresponding editor: Fernando Vega 
discrete models have been used for Atlantic salmon (Forsberg, 1996, 1999) and continuous models for shrimp and tilapia, which have considered the initial population density (Gasca-Leyva et al., 2008; Domínguez-May et al., 2011; Araneda et al., 2013). Continuous models compared to discrete models offer the advantage of predicting future values because they can simulate population variation based on weight and time by using a normal distribution, which is relevant for sowing and selective harvesting (Arnason et al., 1992). Other authors have applied for the same purpose, the Generalized Linear Model Method (Briceño et al., 2010) and quantile regressions (Mayer et al., 2009; Estruch et al., 2017; Jover, 2017).

Most of the current bioeconomic models consider the effect of the initial variation of organisms' size, neglecting the influence that this effect can have over time. Incorporating this factor into models can improve the estimation of marketable biomass, relevant information to determine the OHT. Nile tilapia models have not yet considered a continuous approach structured by weight to address this problem.

In previous works, we calculated the bioeconomic effect of size heterogeneity on commercial production of Nile tilapia. We demonstrated that the quasi-benefit of variable costs had an inversely proportional relationship with the minimum market size (BorregoKim et al., 2020). In this study, we use the results obtained previously to develop a bioeconomic model that includes the dispersion of size and Mms in the production of Nile tilapia and thus provide data on net profit.

\section{MATERIALS AND METHODS}

\section{Data source}

The data used to perform the bioeconomic modeling comes from an experimental study conducted in a commercial tilapia farm (Yaxchilam Farm, Yucatan, Mexico) from February 2015 to January 2016 for 330 days (Borrego-Kim et al., 2020). The organisms were obtained from a batch of 100,000 sex-reversed Nile tilapia (Oreochromis niloticus) fingerlings (Spring Genetics). Briefly, the experimental design consisted of two treatments with the same population density (40 org $\mathrm{m}^{-3} ; 180$ fish) and three replication per treatment. Two seeding strategies were used: heterogeneous seeding (HT) (44-115 g body weight (BW)) and homogeneous seeding (HM) (87-112 g BW). The experimental units consisted of $1,700 \mathrm{~L}$ tanks with a depth of $0.75 \mathrm{~m}$ and a diameter of $2.13 \mathrm{~m}$. A 5.0 HP blower was used to maintain aeration. The area was covered with a shade mesh (70\% sun protection). The feeding rate was $3 \%$ of the biomass distributed three times during the day. The fish were fed a commercial floating pellet containing $35 \%$ crude protein and 3,152 $\mathrm{kcal} \mathrm{kg}^{-1}$ as metabolizable energy. During the first 26 weeks, the fish were fed $3 \%$ of initial biomass; after, the feeding rate was adjusted to $2 \%$ until ending the experiment.

All the fish of each treatment were weighed every 15 days. The procedure consisted of lowering the water level of each tank, taking out all the fish with a net of 1.0 , and dividing them between rectangular tanks of $72 \times 40 \times 35 \mathrm{~cm}$ with aeration to reduce stress. The mortality rate at the final of the experiment was 3.89 and $2.33 \%$ for $\mathrm{HM}$ and HT, respectively. For more details, see Borrego-Kim et al. (2020).

\section{Model description}

The experimental data was used to build a bioeconomic model. The variables considered were weight, stocking density, feed conversion ratio, and marketable sizes.

\section{Biologic sub-model}

The von Bertalanffy model (Von Bertalanffy, 1957) was applied to describe the growth of fish in each population. This model was selected according to the results obtained by previous authors for several commercial tilapia strains (Allaman et al., 2013; Zuniga \& Goycolea-Homann, 2014).

The biological sub-model included the effect of the variation in size in the instantaneous individual growth rate.

This effect considers the dispersion of size in growth during a specific period (Pérez, 2014).

$$
\frac{d x}{d t}=g(x) \pm \varepsilon \quad x(0)=x_{0}
$$

where $g(x)$ represents the growth rate, $\varepsilon \equiv \eta(t, x)$ represents the deviation of the instantaneous individual growth rate, and $x_{0}>0$ represents the initial size of the individual at $t=0$. It is assumed that $g(x)$ it is continuously differentiable and has a positive value in the $[0, \omega]$ interval, $g(0)=g(\omega)=0$ where $\omega$ represents the maximum size of the fish $(\omega>0)$. The deviation of the growth rate (Equation 1), was modeled as follows, with an equation similar to the one proposed by Pauly \& Gaschutz (1979):

$$
\eta(t, x)=w_{0}\left(x_{0}\right)+A e^{-\delta x} \cos (2 \pi(t-B) / \mathrm{C})
$$

where $w_{0}\left(x_{0}\right)$ represents the linear effect of the variation (initial deviation) of the initial size $x_{0}$, which is similar to the linear function for average absolute 
value for variation proposed by Gulland (1971). A, B, and $\mathrm{C}$ are parameters, while $\delta$ is the average change rate of the variation coefficient for the empirical data and can be described as $\delta=\Delta C V(t) / t$; the used coefficient is defined as $C V(t)=s_{x(t)} / \bar{x}$, where $s_{x(t)}$ represents the standard deviation of fish size and $\bar{x}$ represents the average fish size. The change of $C V(t)$ in time was described as $\frac{d(C V(t))}{d t}$. To find the linear relationship of $w_{0}$, the following equation was used

$$
w_{0}\left(x_{0}\right)=m x_{0}-n
$$

where $m$ is the slope (rate of change) and $n$ is the yintercept; Equation 3 represents the initial variation in sizes.

Equation 1 was integrated by the Microsoft Excel Software through the Euler method assuming a time value of one day $(d \tau=1)$

$$
x(t)=x_{0}+\int_{0}^{t}\{g(x(\tau))+\eta(\tau, x(\tau))\} d \tau
$$

\section{Management sub-model}

The initial population density represented as $N_{0}$ had the same value for the HT and HM system. The observed variance for this parameter was higher in the HT system (HM variance $<$ HT variance, $P<0.05$ ), as was expected. The Mms delimited the $x(t)$ value.

The model by Gasca-Leyva et al. (2008) describes the function for the number of organisms with different $x$ sizes at a time $t$, as:

$$
\begin{gathered}
N_{t}(t, x)+(g(x) N(t, x))_{x}=-\mu N(t, x) \\
0<x<\omega, t>0 \\
N(0, x)=N_{0} v_{0}(x) \\
N(t, 0)=0
\end{gathered}
$$

where $\mu$ represents the instantaneous mortality rate $(\mu \geq 0)$, which is assumed to be independent of the organism's size.

The two conditions followed by this model are a) the distribution of sizes $N_{\mathrm{o}}$ is dependent on the probability density function (PDF) $v_{0}(x)$, and b) there is no introduction of new organisms to the system. The partial derivatives of the model indicate that through time the growth of the organisms follows Equation 1; this suggests that the initial variability of the system determines heterogeneity. The $\beta$ coefficient, a PDF, considers the different Mms; this can be seen in the following equation:

$$
v_{0}(x)=\frac{1}{x_{1}-x_{0}} \frac{\Gamma(\alpha+\beta)}{\Gamma(\alpha) \Gamma(\beta)}\left(\frac{x-x_{0}}{x_{1}-x_{0}}\right)^{\alpha-1}\left(1-\frac{x-x_{0}}{x_{1}-x_{0}}\right)^{\beta-1}
$$

with $\Gamma(\alpha)=\int_{0}^{\infty} e^{-x} x^{\alpha-1} d x ; x_{0}<x<x_{1} ; \alpha, \beta>0$.

where $x$ represents the fish size, $\Gamma$ represents the gamma function, $x_{0}$ and $x_{1}$ represents the initial range for the deduction period of growth, $\alpha$ and $\beta$ are defined by $\alpha(x)=\alpha_{1} e^{-\alpha_{2} x}$ and $\beta(x)=\beta_{1} e^{-\beta_{2} x}$. These equations indicate that size heterogeneity over a determined period depends on the initial variability of the organisms and other factors involved in the population dynamics of fish.

The equation for the biomass of the organisms over time $t$ is:

$$
B(t)=\int_{0}^{\infty} x(t) N(t, x) d x
$$

where $\omega$ represents the maximum size of the fish $(\omega>0)$.

\section{Economic sub-model}

Biomass value: the assumptions used for the economic sub-model are found in Table 1. The value of biomass over time was determined by the sum of all individual values (by size) at a specific time in time once organisms reach the Mms. Biomass was established as independent of size.

This equation is represented as

$$
V(t)=p \int_{0}^{w} x(t) N(t, x) d x
$$

The considered costs are the feeding costs $\mathrm{f}(\mathrm{x})$, the labor cost $c_{L}$, and the energy cost $c_{E}$. Therefore, the total accumulated at $t$ days is given by

$$
C(t)=\int_{0}^{t} e^{-\rho \tau}\left(\int_{0}^{\omega} f(x) N(\tau, x) d x+c_{L}+c_{E}\right) d \tau+c_{0}+c_{F}
$$

where $\rho$ represents the daily discount rate, $c_{0}$ represents the cost of the fry, and $c_{F}$ represents the fixed costs (depreciation of the infrastructure and the motor pumps). For calculating the feeding costs the feed conversion index $\xi$ was used, this indicates the ratio between food intake and the size increase of an organism, as shown in the following equation:

$$
f(x)=c_{f} \xi\{g(x)+\eta(t, x)\}
$$

$c_{M}$ is the cost of individual maintenance of the fish per $\operatorname{kg} C_{f}$ represents the cost per $\mathrm{kg}$ of food.

Net benefit: for this model, a single production cycle is considered. The discounted profits function is given by: 
Table 1. Assumptions used for bioeconomic modeling optimal harvesting time in Nile tilapia (Oreochromis niloticus) considering size heterogeneity and minimum marketable size. ${ }^{a}$ Includes the maintenance costs of the infrastructure. bincludes the investment interests and the depreciation of the infrastructure and the motor pumps.

\begin{tabular}{lccc}
\hline Parameter & Symbol & Unit & Value \\
\hline Maximum selling price & $p$ & USD kg $^{-1}$ & 2.31 \\
Fry cost & $C_{S}$ & USD fry $^{-1}$ & 0.28 \\
Labor cost & $C_{L}$ & USD d $^{-1}$ & 10.28 \\
Energy cost & $C_{E}$ & USD d $^{-1}$ & 3.25 \\
Feeding costs & $C_{f}$ & USD kg $^{-1}$ & 0.64 \\
Maintenance cost & $C_{M}$ & USD kg $^{-1}$ & 0.001 \\
Fixed cost $^{\mathrm{b}}$ & $C_{F}$ & USD cycle $^{-1}$ & $1,232.31$ \\
Instantaneous mortality rate & $\mu$ & Fish d $^{-1}$ & 0.00067 \\
Discount rate & $r$ & $\%$ year $^{-1}$ & 7.5 \\
\hline
\end{tabular}

$\operatorname{Max} \underset{t \geq 0}{\prod}(t)=e^{-\rho t} V(t)-C(t)$

s.a.

$$
x(t) \geq x_{T M M}
$$

where $\prod$ is the net benefit at time $t, e$ is the base of the Napierian logarithm, $p=(1+\mathrm{r})^{1 / 365}-1$ is the daily discount rate, $V(t)$ is the value of the biomass, $C(t)$ is the total cost of the production cycle, $\chi(t)$ is the size of fish through time, and $\chi_{T M M}$ is the minimum marketable size.

\section{Statistical analysis}

The growth model's parameterization was performed with Statistica version 12 (StatSoft Inc., Tulsa, OK, USA). The bioeconomic model was made in Microsoft Excel. The accuracy of the model was validated by the prediction of known patterns (Power, 1993; Hernández $\&$ Gasca-Leyva, 2003). The coefficient of determination $\left(\mathrm{R}^{2}\right)$, the mean square error (RMSE), and the Theil's inequality coefficient (U) were used to adjust the growth model (Barlas, 1989). The RMSE is usually divided into three factors that measure the proportion of bias in the average, variance, and covariance. The inequality coefficient $\mathrm{U}$ is limited between 0 and 1 ; a value of zero indicates that the model accurately predicts real values, while a value of 1 means the opposite (Pindyck \& Rubinstein, 1998).

\section{Ethical approval}

The experiments performed were following the National and Institutional guidelines for animal welfare. The tests described complying with the Manual of Good Practices in Aquaculture Production of Tilapia for Food Safety described by García-Ortega \& CalvarioMartínez (2008).

\section{RESULTS}

\section{Growth model}

Table 2 shows the values of the parameters of the von Bertalanffy growth model. All parameters were statistically significant. The statistical indicators of the Theil inequality index and its components are in Table 3. In HT and HM systems, the growth simulation model explained between 92 to $98 \%$ of the observed data variation, except for in HM with $89.4 \%$.

\section{Optimal harvest time}

Figure 1 shows the relative proportion in time between the HM and HT systems of individuals that did not reach the minimum market size. After 150 days and until the end of growth, the HT system had a higher percentage of organisms that did not reach the limit reference point identified as the Mms.

Figure 2 shows the distribution of organisms by Mms for each system, where the vertical dashed line represents the OHT; the HT system shows greater dispersion.

In the HT system, the highest gain was obtained in the Mms $350 \mathrm{~g}$ in an OHT of 196 days and a net profit of USD 3,551.61, while the profit generated in $500 \mathrm{~g}$ was negative (Table 4). The CV in HT showed a significant decrease. Marketable biomass varied between 91.1 and $98.3 \%$ between HT and HM.

Table 5 shows the estimates of OHT in a culture cycle in the HM system. The results show that OHT increases as the Mms increases. The maximization of the net gain indicated a higher profit with USD 3,327.96 in the Mms of $350 \mathrm{~g}$ and a harvest time of 181 days. The lowest benefit of USD 615.43 was obtained in the $M m s=500 \mathrm{~g}$ and with an OHT of 221 days. The CV remained around $30 \%$ and decreased slightly as the harvest day increased. Although the range of marketable 
Table 2. Estimated parameters of the von Bertalanffy growth model of Nile tilapia (Oreochromis niloticus) from two seeding strategies: homogeneous seeding size (HM) and heterogeneous seeding size (HT). ${ }^{\text {a } V a l u e s ~ e s t i m a t e d ~ f r o m ~ t h e ~}$ experimental data. ${ }^{\text {b}}$ Values estimated with Excel's function solver by the least-squares method. PDF: Probability density function.

\begin{tabular}{lcccccr}
\hline \multirow{2}{*}{ Parameter } & \multirow{2}{*}{ Symbol } & \multicolumn{2}{c}{ HM } & & \multicolumn{2}{c}{ HT } \\
\cline { 3 - 4 } \cline { 6 - 7 } & & Estimated value & $t$-value & & Estimated value & $t$-value \\
\hline Catabolism parameter & $a$ & 0.1651 & 3.56 & & 0.1464 & 4.39 \\
Anabolism parameter & $b$ & 0.0155 & 2.82 & & 0.0132 & 3.39 \\
Initial variation slope & $m$ & 0.1078 & 18.15 & & 0.0212 & 15.07 \\
Ordinate of the initial variation & $n$ & -10.67 & -17.94 & & -2.04 & -13.89 \\
Average instantaneous rate & $\delta$ & $0.00049^{\mathrm{a}}$ & & & $0.00003^{\mathrm{a}}$ & \\
Calibration parameter & $A$ & $1.24^{\mathrm{b}}$ & & & $0.75^{\mathrm{b}}$ & \\
Calibration parameter & $B$ & $124.26^{\mathrm{b}}$ & & & $93.48^{\mathrm{b}}$ & \\
Calibration parameter & $C$ & $230.93^{\mathrm{b}}$ & & & $281.79^{\mathrm{b}}$ & \\
Constants for the $(\alpha)$ & $\alpha_{1}$ & 3.76 & 11.40 & & 2.52 & 16.71 \\
Parameter of the $(\alpha)$ PDF & $\alpha_{2}$ & 0.00041 & 2.16 & & 0.00029 & 2.50 \\
Constants for the $(\beta)$ & $\beta_{1}$ & 4.18 & 3.95 & & 3.62 & 12.59 \\
Parameter of the $(\beta)$ PDF & $\beta_{2}$ & 0.00090 & 1.47 & & 0.00101 & 5.53 \\
\hline
\end{tabular}

Table 3. Results of the validation of the von Bertalanffy growth model of Nile tilapia (Oreochromis niloticus) from two seeding strategies: homogeneous seeding size (HM) and heterogeneous seeding size (HT).

\begin{tabular}{|c|c|c|c|c|c|c|c|c|c|}
\hline \multirow{2}{*}{$\begin{array}{l}\text { Statistical validation } \\
\text { parameters }\end{array}$} & \multirow{2}{*}{ Symbol } & \multicolumn{4}{|c|}{ HM } & \multicolumn{4}{|c|}{ HT } \\
\hline & & \multicolumn{4}{|c|}{ Estimated value } & \multicolumn{4}{|c|}{ Estimated value } \\
\hline & & $\mathrm{Q}_{1}$ & $\mathrm{Q}_{2}$ & $\mathrm{Q}_{3}$ & $X_{M A X}$ & $\mathrm{Q}_{1}$ & $\mathrm{Q}_{2}$ & $\mathrm{Q}_{3}$ & $X_{M A X}$ \\
\hline Root mean square error & RMSE & 52.74 & 64.70 & 38.63 & 135.01 & 41.72 & 32.05 & 37.16 & 116.17 \\
\hline Theil index & $\mathrm{U}$ & 0.1234 & 0.1303 & 0.0671 & 0.1810 & 0.1039 & 0.0654 & 0.0647 & 0.1579 \\
\hline Average component & $\mathrm{U}^{\mathrm{M}}$ & 0.7649 & 0.7859 & 0.4091 & 0.3645 & 0.6371 & 0.5023 & 0.0482 & 0.4375 \\
\hline Variance component & $\mathrm{U}^{\mathrm{S}}$ & 0.0532 & 0.0022 & 0.0325 & 0.4017 & 0.0895 & 0.0076 & 0.3903 & 0.4793 \\
\hline Covariance component & $\mathrm{U}^{\mathrm{C}}$ & 0.1818 & 0.2119 & 0.5584 & 0.2339 & 0.2733 & 0.4901 & 0.5614 & 0.0832 \\
\hline
\end{tabular}

biomass was $93.9-99.4 \%$, it was maximized based on the minimum size.

\section{Sensitivity analysis}

The sensitivity analysis results are summarized in Table 6 , in which the most influential economic factors in the tilapia culture system are established. This analysis showed that for both HT and HM, the product's price is the commercial parameter that most contributes to the variation in net profit. To a lesser extent, changes in the OHT impact on the Mms 350 and $400 \mathrm{~g}$, while for 450 and $500 \mathrm{~g}$, it did not reflect any changes.

\section{DISCUSSION}

This work's main contribution is a bioeconomic model for size heterogeneity using a continuous population model that reflects the effect of economic performance on tilapia (Oreochromis spp.) farming. The proposed growth model is not linear and includes the deviation factor of the similar size used by Pérez (2014). The model more accurately predicts the size range at the end of the growth period, which is useful for the industry. Understanding size dispersion lowers economic risk, especially at the time of return on investment.

The problem of heterogeneity was previously addressed for tilapia and white shrimp (Penaeus vannamei) using size-structured bioeconomic models, where the leading cause of this phenomenon was environmental (Araneda et al., 2008, 2011; GascaLeyva et al., 2008; Domínguez-May et al., 2011). Most known models for size dispersion only consider the total biomass harvested, without analyzing the effect that minimum marketable sizes have on this value (Forsberg \& Guttormsen, 2006; Araneda et al., 2011; Domínguez et al., 2011). Our bioeconomic model simulates size dispersion and heterogeneity, focusing on the minimum marketable size, which helps farmers estimate their earnings based on these parameters.

The work results showed a direct positive relationship between the dispersion of the fish size and the optimal harvest time. The benefits generated by the 

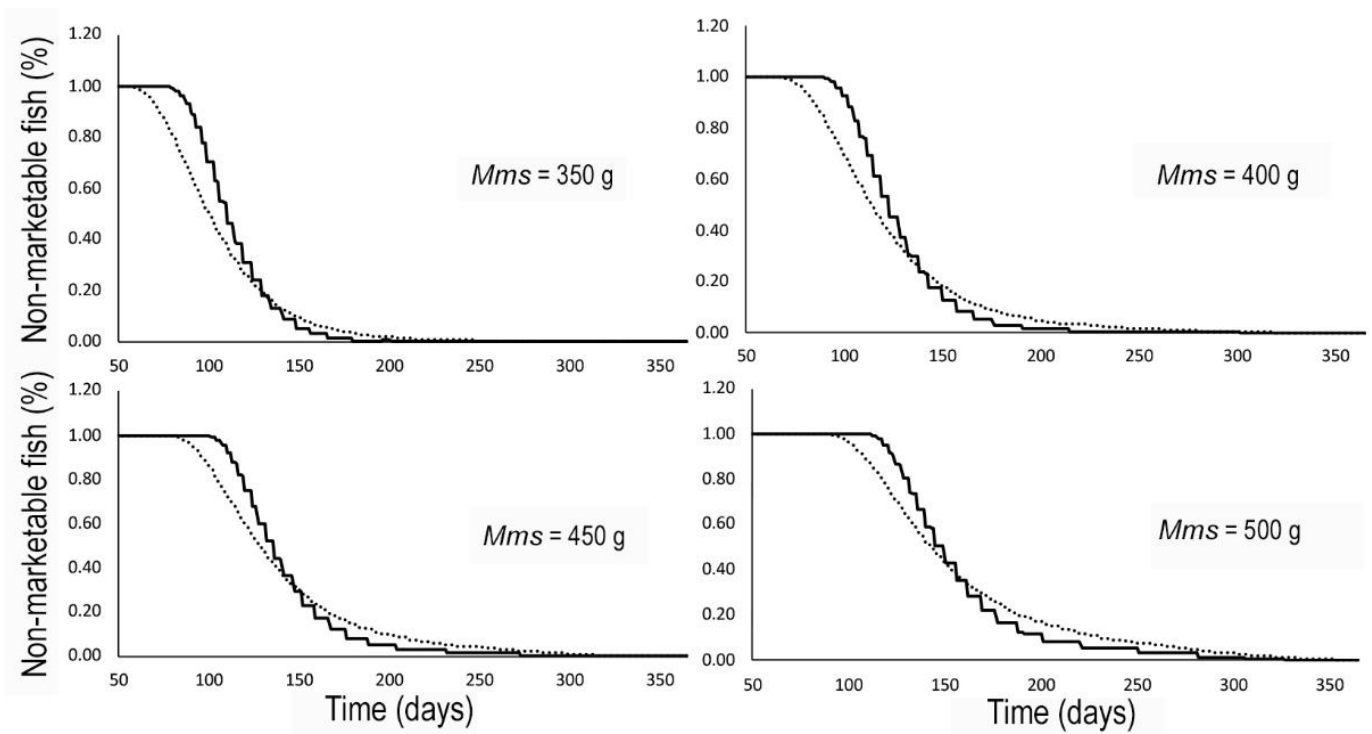

Figure 1. Percentage of fish that do not reach the minimum marketable size in homogeneous (-) and heterogeneous (..) stocking strategies.
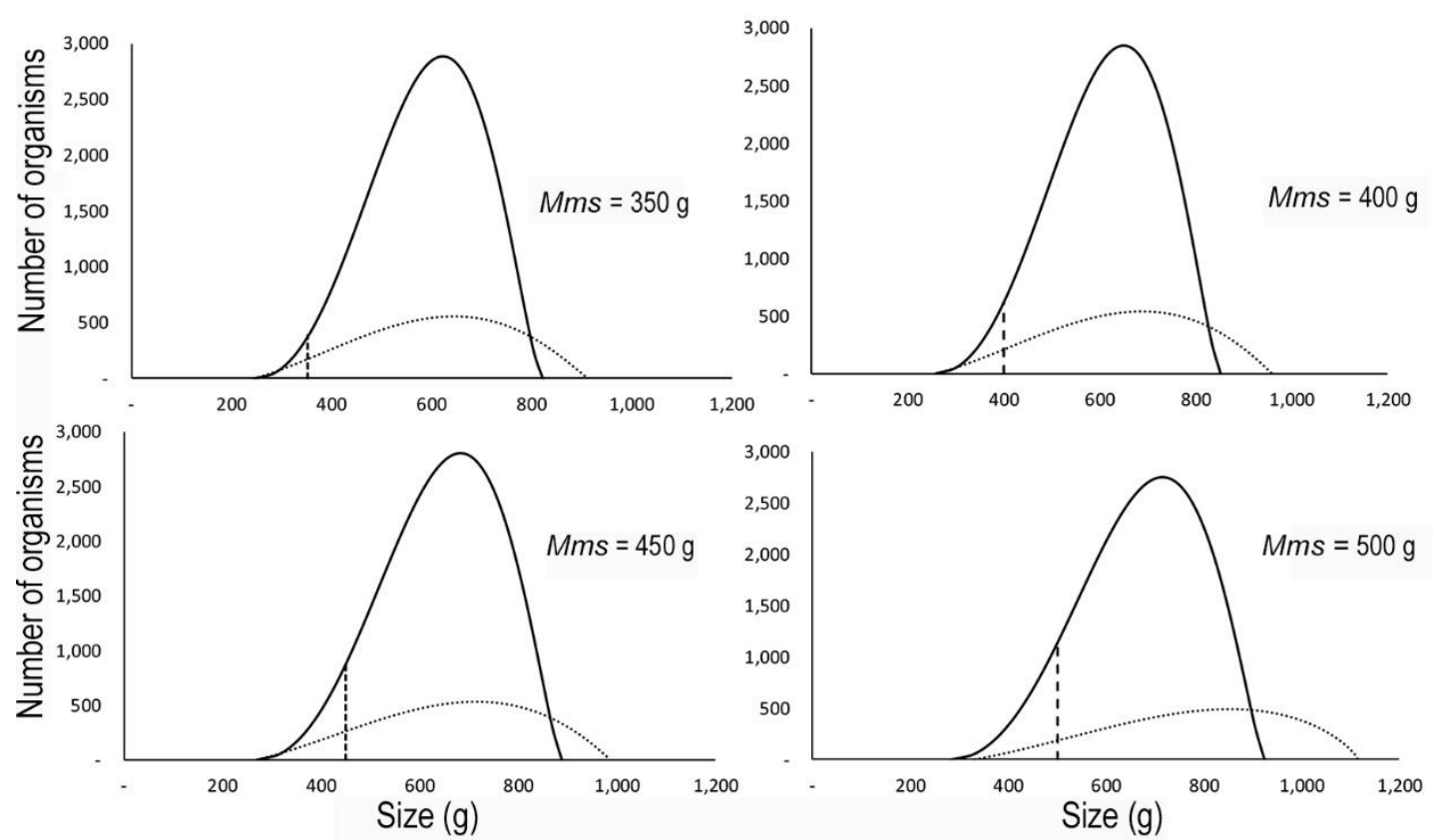

Figure 2. Organisms distribution by minimum marketable size $(M m s)$ in the homogeneous (-) and heterogeneous (..) seeding strategies. The vertical dashed line represents the optimal harvest time (OHT).

HT system were lower than those obtained by the $\mathrm{HM}$, possibly due to the reduction in marketable biomass and its impact on economic performance. The OHT for the HT system was 196-229 days for the Mms of 350,400 , and $500 \mathrm{~g}$. This time was shorter in the HM strategy, where the OHT was 181-221 days for Mms 350,400 , and $450 \mathrm{~g}$. The $M m s=500 \mathrm{~g}$ presented a negative net profit of USD 235.96 in the HT system, while in the HM, the net profit was USD 615.40. The economic results are consistent with the conclusions of
Pérez et al. (2012) and Borrego-Kim et al. (2020), in which they indicated that heterogeneity harms the optimization of biomass and yield as a function of time.

The OHT and final weight were higher in the HT system than in the HM. The average sizes observed in the HT system for the Mms of 350, 400, 450, and $500 \mathrm{~g}$ were $628.84,664.30,685.04$, and $793.05 \mathrm{~g}$, while in $\mathrm{HM}$, the observed values were 570.31, 593.63, 619.57 and $647.28 \mathrm{~g}$. Bjørndal (1988), deduced that the OHT and size increase with variable prices. The present model 
Table 4. Optimal harvest time (OHT) of Nile tilapia (Oreochromis niloticus) from heterogeneous seeding size (HT) considering minimum marketable sizes.

\begin{tabular}{lccccc}
\hline \multirow{2}{*}{ Parameter } & \multirow{2}{*}{ Unit } & \multicolumn{4}{c}{ Minimum marketable sizes } \\
& & & $400 \mathrm{~g}$ & $450 \mathrm{~g}$ & $500 \mathrm{~g}$ \\
\hline Production & & & & & \\
Optimal harvest time (OHT) & $\mathrm{d}$ & 196 & 216 & 229 & 296 \\
Min and max weight & $\mathrm{g}$ & $350.2-912.9$ & $400.9-958.9$ & $450.2-985.8$ & $500.1-116.5$ \\
CV & $\%$ & 29.55 & 29.14 & 28.91 & 27.13 \\
Survival rate & $\%$ & 87.75 & 86.58 & 85.84 & 82.08 \\
Total biomass & $\mathrm{kg}$ & $25,243.33$ & $26,470.20$ & $27,639.95$ & $30,516.67$ \\
Viable biomass at the OHT & $\%$ & 99.1 & 98.3 & 96.9 & 98.3 \\
Sales revenue & & & & & \\
Price & USD kg-1 & 2.35 & 2.35 & 2.35 & 2.35 \\
Biomass value & USD & $56,389.48$ & $58,390.06$ & $58,811.39$ & $66,288.58$ \\
Costs & & & & & \\
Fixed costs & USD & $1,232.31$ & $1,232.31$ & $1,232.31$ & $1,232.31$ \\
Food & USD & $33,426.31$ & $35,604.51$ & $36,863.14$ & $43,163.18$ \\
Maintenance & USD & $2,771.64$ & $3,268.49$ & $3,602.07$ & $5,432.52$ \\
Labor & USD & $1,987.07$ & $2,184.50$ & $2,312.41$ & $2,966.44$ \\
Energy & USD & 628.04 & 690.44 & 73.87 & 937.58 \\
Fry & USD & $12,792.50$ & $12,792.50$ & $12,792.50$ & $12,792.50$ \\
Total & USD & $52,837.87$ & $55,772.75$ & $56,876.30$ & $66,524.53$ \\
Profits & & & & & \\
Net profit & USD & $3,551.61$ & $2,617.31$ & $1,278.09$ & -235.96 \\
\hline
\end{tabular}

Table 5. Optimal harvest time (OHT) of Nile tilapia (Oreochromis niloticus) from homogeneous seeding size (HM) considering minimum marketable sizes.

\begin{tabular}{|c|c|c|c|c|c|}
\hline \multirow{2}{*}{ Parameters } & \multirow{2}{*}{ Unit } & \multicolumn{4}{|c|}{ Minimum marketable sizes } \\
\hline & & $350 \mathrm{~g}$ & $400 \mathrm{~g}$ & $450 \mathrm{~g}$ & $500 \mathrm{~g}$ \\
\hline \multicolumn{6}{|l|}{ Production } \\
\hline Optimal harvest time (OHT) & d & 181 & 191 & 204 & 221 \\
\hline Min and max weight & $\mathrm{g}$ & $\begin{array}{c}353.1- \\
822.9\end{array}$ & $400.8-852.9$ & $450.1-887.2$ & $500.7-925.3$ \\
\hline $\mathrm{CV}$ & $\%$ & 29.90 & 29.55 & 29.31 & 29.23 \\
\hline Survival rate & $\%$ & 88.62 & 88.02 & 87.26 & 86.27 \\
\hline Total biomass & $\mathrm{kg}$ & $24,221.01$ & $25,092.29$ & $25,932.75$ & $26,959.47$ \\
\hline Viable biomass at the OHT & $\%$ & 99.4 & 98.2 & 96.2 & 93.4 \\
\hline \multicolumn{6}{|l|}{ Sales revenue } \\
\hline Price & USD kg-1 & 2.31 & 2.31 & 2.31 & 2.31 \\
\hline Biomass value & USD & $53,902.69$ & $55,416.43$ & $56,751.98$ & $57,700.89$ \\
\hline \multicolumn{6}{|l|}{ Costs } \\
\hline Fixed costs & USD & $1,232.31$ & $1,232.31$ & $1,232.31$ & $1,232.31$ \\
\hline Food & USD & $31,873.33$ & $33,390.35$ & $35,075.49$ & $36,873.62$ \\
\hline Maintenance & USD & $2,257.65$ & $2,495.40$ & $2,815.13$ & $3,247.29$ \\
\hline Labor & USD & $1,838.48$ & $1,937.59$ & $2,066.14$ & $2,233.74$ \\
\hline Energy & USD & 581.08 & 612.40 & 653.03 & 706.00 \\
\hline Fry & USD & $12,792.50$ & $12,792.50$ & $12,792.50$ & $12,792.50$ \\
\hline Total & USD & $50,574.73$ & $52,460.55$ & $54,634.60$ & $57,085.46$ \\
\hline \multicolumn{6}{|l|}{ Profits } \\
\hline Net profit & USD & $3,327.96$ & $2,955.88$ & $2,117.38$ & 615.43 \\
\hline
\end{tabular}


Table 6. Sensitivity analysis considering the price and the main production costs at different minimum marketable sizes $(M m s)$. HT: heterogeneous seeding size, HM: homogeneous seeding size; OHT: optimal harvest time.

\begin{tabular}{|c|c|c|c|c|c|c|c|}
\hline \multirow{3}{*}{$M m s$} & \multirow{3}{*}{ Parameter } & \multirow{3}{*}{ Concept } & \multirow{3}{*}{$\begin{array}{c}\text { Variation } \\
(\%)\end{array}$} & \multicolumn{4}{|c|}{ System } \\
\hline & & & & \multicolumn{2}{|r|}{ HT } & \multicolumn{2}{|c|}{ HM } \\
\hline & & & & OHT (\%) & Net profit (\%) & OHT (\%) & Net profit (\%) \\
\hline \multirow{6}{*}{$350 \mathrm{~g}$} & \multirow[b]{2}{*}{$\mathrm{p}$} & \multirow{2}{*}{ Price } & -10 & -0.55 & -161.42 & -3.06 & -158.0 \\
\hline & & & +10 & 11.05 & 169.46 & 8.67 & 163.17 \\
\hline & \multirow[b]{2}{*}{$c_{f}$} & \multirow{2}{*}{ Feeding costs } & -10 & 11.05 & 101.33 & 8.67 & 96.95 \\
\hline & & & +10 & -0.55 & 95.34 & 0 & -94.12 \\
\hline & \multirow[b]{2}{*}{$c_{M}$} & \multirow{2}{*}{ Maintenance cost } & -10 & 1.10 & 6.85 & 4.08 & -7.80 \\
\hline & & & +10 & -0.55 & -6.77 & 0 & 8.30 \\
\hline \multirow{6}{*}{$400 \mathrm{~g}$} & \multirow{2}{*}{$\mathrm{p}$} & \multirow{2}{*}{ Price } & -10 & 0 & -187.48 & -6.48 & -218.46 \\
\hline & & & +10 & 12.57 & 189.40 & 7.41 & 225.46 \\
\hline & \multirow{2}{*}{$c_{f}$} & \multirow{2}{*}{ Feeding cost } & -10 & 0.52 & 112.97 & 3.70 & 137.16 \\
\hline & & & +10 & 0 & -112.96 & -6.48 & -133.78 \\
\hline & \multirow[b]{2}{*}{$c_{M}$} & \multirow{2}{*}{ Maintenance cost } & -10 & 0 & 8.44 & 0 & 12.49 \\
\hline & & & +10 & 0 & -8.44 & 0 & -12.49 \\
\hline \multirow{6}{*}{$450 \mathrm{~g}$} & \multirow{2}{*}{$\mathrm{p}$} & \multirow{2}{*}{ Price } & -10 & 0 & -268.03 & -3.06 & -456.24 \\
\hline & & & +10 & 0 & 268.03 & 10.04 & 481.25 \\
\hline & \multirow{2}{*}{$c_{f}$} & \multirow{2}{*}{ Feeding cost } & -10 & 0 & 165.66 & 10.04 & 326.85 \\
\hline & & & +10 & 0 & -165.65 & -3.06 & -287.01 \\
\hline & \multirow[b]{2}{*}{$c_{M}$} & \multirow{2}{*}{ Maintenance cost } & -10 & 0 & 13.30 & 0 & 31.48 \\
\hline & & & +10 & 0 & -13.30 & 10.04 & -28.18 \\
\hline \multirow{6}{*}{$500 \mathrm{~g}$} & \multirow{2}{*}{$\mathrm{p}$} & \multirow{2}{*}{ Price } & -10 & 0 & -937.57 & - & - \\
\hline & & & +10 & 0 & 37.57 & - & - \\
\hline & \multirow{2}{*}{$c_{f}$} & Feeding cost & -10 & 0 & 599.15 & - & - \\
\hline & & Feeaing cost & +10 & 0 & -599.15 & - & - \\
\hline & $c$ & Maintenance cost & -10 & 0 & 52.76 & - & - \\
\hline & $c_{M}$ & & +10 & 0 & -52.76 & - & - \\
\hline
\end{tabular}

did not consider different prices by size in the bioeconomic analysis because in the local tilapia market, the production is sold on-farm through intermediaries, and at a single sale price. However, the studies addressed in these lines of work may be considered in the future. The HM and HT systems' dependence assumed at $t=0$ and the initial sizes in the 87-112 and 44-155 g intervals, respectively, were similar to the initial sizes considered in our previous work (Borrego-Kim et al., 2020).

The $10 \%$ increase in food cost and maintenance showed significant differences in OHT in both strategies. When the price increases $(10 \%)$, it induces an increase in the growth period in the Mms of 350 and $400 \mathrm{~g}$. The OHT of the Mms 450 and $500 \mathrm{~g}$ were independent of the price changes. The analysis coincided with other short-term bioeconomic studies, where the sale price and food costs are sensitive factors for optimal management (Hernández-Llamas et al., 2004; Saiti et al., 2007; Sánchez-Zazueta \& Martínez-
Cordero, 2009; Zuniga-Jara \& Goycolea-Homann, 2014).

Regarding the selection process, the results coincide with the reports by Azaza et al. (2013), and Khaw et al. (2016), in which the organisms with less dispersion contributes to obtaining more significant economic benefits. A common practice in aquaculture is to repeatedly select organisms during culture to reduce size variation during growth. This strategy only occurs due to market demand for organisms of uniform size (Sae-Lim et al., 2013). Some authors have suggested that this handling affects the health and well-being of fish (Sanches \& Piana, 2019) and generates higher labor costs. The results of the HM strategy in this work demonstrate that the size dispersion is smaller when the biological model considers a low initial distribution.

On the other hand, the observed relationship between OHT and heterogeneity contradicts the results obtained by Araneda et al. (2011), and Domínguez- 
May et al. (2011), for shrimp and tilapia, respectively. Following the recommendation of Peacor et al. (2007), those authors considered the dependency period in the data analysis (days affected after storage, $t>0$ ), to evaluate the effect of population density and portion size, concluding that heterogeneity reduces the harvest time. Those studies considered the average size of the population, unlike the present work, where we used dispersion indicators. Another difference with the previously cited models is that the current model considers heterogeneity over time, a closer approach to reality than in a specific period.

Growth models that include size dispersion lead to useful and practical recommendations for the tilapia industry. The results showed that the net benefits were significantly higher in the HM system than the HT, which indicates that it is advisable to select individuals of homogeneous sizes to obtain higher profits. Fish that do not reach Mms are likely to become an economic loss rather than a benefit. Therefore, it is not recommended to keep them in production as they will negatively affect profitability in the short term. This model can become a reference for practical management decisions in fish populations with heterogeneous growth.

\section{ACKNOWLEDGMENTS}

We thank Dr. J.C. Seijo from UMM for his valuable comments made during the work. We acknowledge the National Science and Technology Council (CONACYT) for the PBK's Ph.D. scholarship (grant \#360286).

\section{REFERENCES}

Allaman, I.B., Reis-Neto, R.V., Freitas, R.T.F.D., Freato, T.A., Lago, A.D.A., Costa, A.C. \& Lima, R.R.D. 2013. Weight and morphometric growth of different strains of tilapia (Oreochromis sp.). Revista Brasileira de Zootecnia, 42(5): 305-311. doi:10.1590/S151635982013000500001

Araneda, M.E., Hernández, J. \& Gasca-Leyva, E. 2011. Optimal harvesting time of farmed aquatic populations with nonlinear size-heterogeneous growth. Natural Resource Modeling, 24: 477-513. doi: 10.1111/j.19397445.2011.00099.x

Araneda, M., Pérez, E.P. \& Gasca-Leyva, E. 2008. White shrimp Penaeus vannamei culture in freshwater at three densities: condition state based on length and weight. Aquaculture, 283: 13-18. doi: 10.1016/j.aquaculture. 2008

Araneda, M.E., Hernández, J.M., Gasca-Leyva, E. \& Vela, M.A. 2013. Growth modelling, including size heterogeneity: application to the intensive culture of white shrimp ( $P$. vannamei) in freshwater. Aquaculture Engineering, 56: 1-12. doi: 10.1016/j.aquaeng. 2013.03.003

Arnason, A.N., Papst, M.H. \& Hopky, G.E. 1992. Modelling the increase in variance of fish weight. Canadian Journal of Fisheries and Aquatic Sciences, 49: 2-16. doi: 10.1139/f92-001

Azaza, M.S., Assad, A., Maghrbi, W. \& El-Cafsi, M. 2013. The effects of rearing density on growth, size heterogeneity, and inter-individual variation of feed intake in monosex male Nile tilapia Oreochromis niloticus L. Animal, 7: 1865-1874. doi: 10.1017/ S1751731113001493

Barbosa, J.M., Brugiolo, S.S.S., Carolsfeld, J. \& Leitão, S.S. 2006. Heterogeneous growth in fingerlings of the Nile tilapia Oreochromis niloticus: effects of density and initial size variability. Brazilian Journal of Biology, 66: 537-541. doi: 10.1590/S1519-6984200 6000300020

Barki, A., Harpaz, S., Hulata, G. \& Karplus, I. 2000. Effects of larger fish and size grading on growth and size variation in fingerling silver perch. Aquaculture International, 8: 391-401. doi: 10.1023/A:1009274 726380

Barlas, Y. 1989. Multiple tests for validation of system dynamics type of simulation models. European Journal of Operational Research, 42: 59-87. doi.org/10.1016/ 0377-2217(89)90059-3

Bjørndal, T. 1988. Optimal harvesting of farmed fish. Marine Resource Economics, 5(2): 139-159.

Borrego-Kim, P., Gullian-Klanian, M. \& Seijo, J.C. 2020. Effect of size heterogeneity of Nile tilapia (Oreochromis niloticus) on the optimal harvest time: a bioeconomics approach. Latin American Journal of Aquatic Research, 48: 65-73. doi: 10.3856/vol48issue1-fulltext-2360

Briceño, F., Mascaró, M. \& Rosas, C. 2010. GLMMbased modelling of growth in juvenile Octopus maya siblings: does growth depend on initial size? ICES Journal of Marine Sciences, 67: 1509-1516. doi: 10.1093/icesjms/fsq038

Cai, J.N., Leung, P.S., Luo, Y.J., Yuan, X.H. \& Yuan, Y. 2018. Improving the performance of tilapia farming under climate variation: perspective from bioeconomic modelling. FAO Fisheries and Aquaculture Technical Paper, 608: 64 pp.

Domínguez-May, R., Poot-López, G.R., Hernández, J. \& Gasca-Leyva, E. 2020. Dynamic optimal ration size in tilapia culture: economic and environmental considerations. Ecological Modelling, 420: 108930. doi: 10.1016/j.ecolmodel.2020.108930 
Domínguez-May, R., Hernández, J.M., Gasca-Leyva, E. \& Poot-López, G.R. 2011. Effect of ration and size heterogeneity on harvest time: tilapia culture in Yucatan, Mexico. Aquaculture Economics \& Management, 15: 278-301. doi: 10.1080/13657305.2011. 624575

Estruch, V.D., Mayer, P., Roig, B. \& Jover, M. 2017. Developing a new tool based on a quantile regression mixed-TGC model for optimizing gilthead sea bream (Sparus aurata L) farm management. Aquaculture Research, 48: 5901-5912. doi: 10.1111/are.13414

Food and Agriculture Organization (FAO). 2016. The state of world fisheries and aquaculture. Contributing to food security and nutrition for all. FAO, Rome.

Føre, M., Frank, K., Norton, T., Svendsen, E., Alfredsen, J.A., Dempster, T., et al. 2018. Precision fish farming: a new framework to improve production in aquaculture. Biosystem Engineering, 173: 176-193. doi: 10.1016/j.biosystemseng.2017.10.014

Forsberg, O.I. 1996. Optimal stocking and harvesting of size-structured farmed fish: a multi-period linear programming approach. Mathematics and Computers in Simulation, 42: 299-305. doi: 10.1016/0378-4754 (95)00132-8

Forsberg, O.I. 1999. Optimal harvesting of farmed Atlantic salmon at two cohort management strategies and different harvest operation restrictions. Aquaculture Economics \& Management, 3: 143-158. doi: $10.1080 / 13657309909380241$

Forsberg, O.I. \& Guttormsen, A.G. 2006. The value of information in salmon farming. Harvesting the right fish at the right time. Aquaculture Economics \& Management, 10: 183-200. doi: 10.1080/13657300600 985215

García-Ortega, A. \& Calvario-Martínez, O. 2008. Manual de buenas prácticas de producción acuícola de tilapia para la inocuidad alimentaria. Centro de Investigación en Alimentación y Desarrollo, SENASICA/ SAGARPA, Ciudad de México. [https://www.gob.mx/ cms/uploads/attachment/file/167794/7_Manual_Tilap ia.pdf]. Reviewed: November 16, 2019.

Gasca-Leyva, E., Hernández, J.M. \& Veliov, V.M. 2008. Optimal harvesting time in a size-heterogeneous population. Ecological Modelling, 210: 161-168. doi: 10.1016/j.ecolmodel.2007.07.018

Gulland, J.A. 1971. Manual de métodos para la evaluación de las poblaciones de peces. Editorial Acribia, Zaragoza.

Gullian-Klanian, M. \& Arámburu-Adame, C. 2013. Performance of Nile tilapia Oreochromis niloticus fingerlings in a hyper-intensive recirculating aquaculture system with low water exchange. Latin American Journal of Aquatic Research, 41: 150-162. doi: 103856/vol41-issue1-fulltext-12
Gullian, M., Espinosa-Faller, F.J., Nuñez A. \& LópezBarahona, N. 2012. Effect of turbidity on the ultraviolet disinfection performance in recirculating aquaculture systems with low water exchange. Aquaculture Research, 43(4): 595-606. doi: 10.1111/j.13652109.2011.02866.x

Hernández, J. \& Gasca-Leyva, E. 2003. A size distribution model applied to fish farming. In: Dimov, I., Lirkov, I. \& Margenov, S.Z.Z. (Eds.). Numerical methods and applications. Springer, Berlin, pp. 221-229.

Hernández-Llamas, A., González-Becerril, A., Hernández-Vázquez, S. \& Escutia-Zuñiga, S. 2004. Bioeconomic analysis of intensive production of the blue shrimp Litopenaeus stylirostris (Stimpson). Aquaculture Research, 35: 103-111. doi: 10.1111/j. 1365-2109.2004.00980.x

Huang, W.B. \& Chiu, T.S. 1997. Effects of stocking density on survival, growth, size variation, and production of tilapia fry. Aquaculture Research, 28: 165-173. doi: 10.1111/j.1365-2109.1997.tb01029.x

Jover, M. 2017. The quantile regression mixed growth model can help to improve the productivity in gilthead sea bream (Sparus aurata) and European sea bass (Dicentrarchus labrax) growing in marine farms. Journal of Aquaculture \& Marine Biology, 6: 4-6. doi: 10.15406/jamb. 2017.06.00161

Khaw, H.L., Ponzoni, R.W., Yee, H.Y., Aziz, M.A. \& Bijma, P. 2016. Genetic and non-genetic indirect effects for harvest weight in the GIFT strain of Nile tilapia (Oreochromis niloticus). Aquaculture, 450: 154-161. doi: 10.1016/j.aquaculture.2015.07.033

Klinger, D. \& Naylor, R. 2012. Searching for solutions in aquaculture: charting a sustainable course. Annual Review of Environment and Resources, 37: 247-276. doi: 10.1146/annurev-environ-021111-161531

Llorente, I. \& Luna, L. 2016. Bioeconomic modelling in aquaculture: an overview of the literature. Aquaculture International, 24: 931-948. doi: 10.1007/s10499-0159962-z

Martínez, J.A. \& Seijo, J.C. 2001. Economics of risk and uncertainty of alternative water exchange and aeration rates in semi-intensive shrimp culture systems. Aquaculture Economics \& Management, 5: 129-145. doi: 10.1080/13657300109380283

Mayer, P., Estruch, V., Martí, P. \& Jover, M. 2009. Use of quantile regression and discriminant analysis to describe growth patterns in farmed gilthead sea bream (Sparus aurata). Aquaculture, 292: 30-36. doi: 10.1016/j.aquaculture.2009.03.035

Moreno-Figueroa, L.D., Naranjo-Páramo, J., HernándezLlamas, A., Vargas-Mendieta, M., HernándezGurrola, J.A. \& Villarreal-Colmenares, H. 2018. 
Performance of a photo-heterotrophic, hypersaline system for intensive cultivation of white leg shrimp (Litopenaeus vannamei) with minimal water replacement in lined ponds using a stochastic approach. Aquaculture Research, 49: 57-67. doi: 10.1111/are. 13432

Núñez-Amao, L., Naranjo-Páramo, J., HernándezLlamas, A., Vargas-Mendieta, M. \& Villarreal, H. 2019. Estimating production costs of preadult redclaw crayfish, Cherax quadricarinatus reared in a commercial nursery system: a stochastic bioeconomic approach. Journal of the World Aquaculture Society, 50: 172-185. doi: 10.1111/jwas. 12554

Palada de Vera, M.S. \& Eknath, A.E. 1993. Predictability of individual growth rates in tilapia. Aquaculture, 111: 147-158. doi: 10.1016/0044-8486(93)90033-U

Pauly, D. \& Gaschutz, G. 1979. A simple method for fitting growth curve data, with a program for pocket calculators. ICES Council Meeting Papers, 26 pp.

Peacor, S.D., Bence, J.R. \& Pfister, C.A. 2007. The effect of size-dependent growth and environmental factors on animal size variability. Theoretical Population Biology, 71: 80-94. doi: 10.1016/j.tpb.2006.08.005

Pérez, E.P. 2014. Economic effects of the multiple harvest's strategy in the culture of northern scallop Argopecten purpuratus: an opportunity to improve competitiveness. Latin American Journal of Aquatic Research, 42: 180-191. doi: 10.3856/vol42-issue1fulltext-15

Pérez, E.P., Araya, A., Araneda, M. \& Zúñiga, C. 2012. Bioeconomic effect from the size selection in red abalone intensive culture Haliotis rufescens as a production strategy. Aquaculture International, 20: 333-345. doi: 10.1007/s10499-011-9461-9

Pindyck, R.S. \& Rubinfeld, D.L. 1998. Econometric models and economic forecasts. Irwin/McGraw-Hill, Boston.

Power, M. 1993. The predictive validation of ecological and environmental models. Ecological Modelling, 68: 33-50. doi: 10.1016/0304-3800(93)90106-3

Received: 16 January 2020; Accepted: 22 May 2020
Sae-Lim, P., Kause, A., Mulder, H.A., Martin, K.E., Barfoot, A.J., Parsons, J.E., et al. 2013. Genotype-byenvironment interaction of growth traits in rainbow trout (Oncorhynchus mykiss): a continental scale study. Journal of Animal Science, 91: 5572-5581. doi: 10.2527/jas.2012-5949

Saiti, F., Jamu, D.M., Chisala, B. \& Kambewa, P. 2007. Simulation of optimal harvesting strategies for smallscale mixed-sex tilapia (Oreochromis shiranus Boulenger 1896) ponds using a bio-economic model. Aquaculture Research, 38: 340-350. doi: 10.1111/j. 1365-2109.2007.01671.x

Sanches, R.A.K. \& Piana, P.A. 2019. The influence of catch-and-release on mortality of Salminus brasiliensis (Cuvier, 1816). Brazilian Journal of Biology. doi: 10.1590/1519-6984.204168

Sánchez-Zazueta, E. \& Martínez-Cordero, F.J. 2009. Economic risk assessment of a semi-intensive shrimp farm in Sinaloa, Mexico. Aquaculture Economics \& Management, 13: 312-327. doi: 10.1080/13657300 903351685

Santos, V.B., Yoshihara, E., Fonseca de Freitas, R.T. \& Neto, R.V.R. 2008. Exponential growth model of Nile tilapia (Oreochromis niloticus) strains considering heteroscedastic variance. Aquaculture, 274: 96-100. doi: 10.1016/j.aquaculture.2007.11.005

Seijo, J.C. 2004. Risk of exceeding bioeconomic limit reference points in shrimp aquaculture systems. Aquaculture Economics \& Management, 8: 201-212. doi: 10.1080/136573004 09380363

Shamshak, G.L. \& Anderson, J.L. 2009. Dynamic stochastic adaptive bioeconomic model of offshore bluefin tuna aquaculture. Aquaculture Economics \& Management, 13: 155-175. doi: 10.1080/1365730090 2885451

Von Bertalanffy, L. 1957. Quantitative laws in metabolism and growth. Quarterly Review of Biology, 32: 217-231. doi: 10.1086/401873

Zuniga-Jara, S. \& Goycolea-Homann, M. 2014. A bioeconomic model for red tilapia culture on the coast of Ecuador. Aquaculture International, 22: 339-359. doi: 10.1007/s10499-013-9643-8 